\title{
CONSTITUIR, ORDENAR Y ORGANIZAR DESDE LA FICCIÓN: NARRATIVAS JURÍDICAS Y LITERARIAS QUE FUNDARON EL ESTADO ARGENTINO
}

\section{CONSTITUIR, ORDENAR E ORGANIZAR A PARTIR DE FICÇÃO: NARRATIVAS JURÍDICAS E LITERÁRIAS QUE FUNDARAM O ESTADO ARGENTINO}

Gonzalo Ana Dobratinich ${ }^{1}$

RESUMEN: Desde los aportes epistemológicos que ofrece el vínculo "derecho y literatura", el presente trabajo tiene como propósito para examinar la incidencia que tuvieron las narraciones literarias en la formación del Estado Argentino en el siglo XIX. Numerosas/os autoras/es se han valido del recurso de la ficción como herramienta para desplegar y transmitir determinadas perspectivas ideológicas con marcada incidencia en el ámbito del derecho. Las perspectivas de orden, organización y constitución del Estado Argentino, se plasman en textos literarios de manera previa al despliegue que luego tendrán en los textos jurídicos. Narrativas como La Lira Argentina, La cautiva, El matadero, Amalia o Facundo, permiten visibilizar no solo procesos estéticos de creación y producción sino también marcadas posiciones jurídicas sobre la forma de estructuración política.

Palabras clave: Filosofía del Derecho; Derecho y literatura, ficción; Historia constitucional; Narratología.

RESUMO: A partir das contribuições epistemológicas oferecidas pelo vínculo "direito e literatura", o presente trabalho visa examinar a incidência que as narrativas literárias tiveram na formação do Estado argentino no século XIX. Muitos autores têm utilizado o recurso da ficção como ferramenta para expor e transmitir certas perspectivas ideológicas com forte impacto no campo do direito. As perspectivas de ordem, organização e constituição do Estado argentino se refletem em textos literários

\footnotetext{
${ }^{1}$ Investigador del Consejo Nacional de Investigaciones Científicas y Técnicas (CONICET) en el Instituto de Investigaciones Jurídicas y Sociales “A. L. Gioja” (Facultad de Derecho de la Universidad de Buenos Aires, Buenos Aires, Argentina). Doctorando en Derecho (Universidad de Buenos Aires - Universidad de Málaga, España). Magister en Filosofía del Derecho (UBA). Profesor (UBA-UNPAZ). Orcid: https://orcid.org/0000-0002-6548-8700. gonzaloanadobra@gmail.com.
} 
anteriores, que posteriormente aparecerão nos textos jurídicos. Narrativas como $\mathrm{La}$ Lira Argentina, La cautiva, El matadero, Amalia ou Facundo, permitem tornar visíveis não só processos estéticos de criação e produção, mas também posições jurídicas fortes sobre a forma de estruturação política.

Palavras-chave: Filosofia do Fireito; Direito e literatura ficção; História constitucional; Narratologia.

Sumario: 1. Introducción; 2. Independencia, ficciones y estado; 3. Escritura y constitución del estadio bárbaro; 3.1 Poesía; 4. Conclusiones; 5. Referencias.

\section{INTRODUCCIÓN}

La literatura ha venido a ocupar, en unas condiciones históricas que no son simplemente lingüisticas, un lugar siempre abierto a una suerte de juridicidad [juridicité] subversiva.-

La filosofía como institución

La literatura argentina desdobla una fuente valiosa e inagotable de concepciones teóricas y modelos de lectura en torno a lo jurídico (CÁRCOVA, DOUGLAS PRICE, RUIZ, 2014, pp. 15-22; CIURO CALDANI, 1991, pp. 37-39; MARÍ, 2002, pp. 217-254; MARTYNIUK, 2011, pp. 55-68, ROGGERO, 2015, pp. 9-28). La escrupulosa escritura de Borges que recita "Bienaventurados los que no tienen hambre de justicia, porque / saben que nuestra suerte, adversa o piadosa, es obra del azar, / que es inescrutable" (BORGES, 2013, p. 328), ¿puede encontrar su correspondencia con la liviandad profana de Arlt que escribe "qué regocijo nos engrandece las almas cuando quebrantamos la ley y entramos sabiendo en el pecado"? (ARLT, 2004, p. 32). Este fascinante contrapunto debate un modelo de literatura y una forma de comprender el metalenguaje estético de lo cotidiano (MARTYNIUK, 2006, pp. 15-18). Pero también no podemos pasar por alto que las formaciones literarias se inmiscuyen en temáticas jurídicas, lo que nos autoriza una lectura en clave "iusliteraria" (CALVO GONZÁLEZ, 2016b, p. 12; CALVO GONZÁLEZ, 2018, pp. 3-44; CALVO GONZÁLEZ, 2019, pp. 105-137). Esta unión debe comprenderse desde las condiciones que comparten en paralelo desde las 
discontinuidades, rupturas, refuerzos, niveles y encuadres que se producen entre ambas disciplinas (FOUCAULT, 2008, pp. 18-19).

En uno de sus pasajes, la universal obra de Sarmiento, Facundo o civilización y barbarie en las pampas argentinas expone: "En las ciudades había libros, ideas, espíritu municipal, juzgados, derechos, leyes, educación, todos los puntos de contacto y de mancomunidad que tenemos con los europeos" (SARMIENTO, 1962, p. 61). La preocupación que obliga a la prosa, suspende el referente global y permite la pluralidad de significados. El autor mismo, directa o indirectamente, nos propone una lectura de perspectivas jurídicas. Desde esta ecuación metodológica podremos hacer una lectura y tomarnos la licencia de proponer claves interpretativas en torno a otros textos literarios cardinales.

\section{INDEPENDENCIA, FICCIONES Y ESTADO.}

Los poetas son los legisladores no reconocidos del mundo.A defence of poetry

El período conocido como "Formación del Estado Argentino" se inicia con la Revolución de Mayo de 1810 y culmina con la organización de un nuevo gobierno tras la batalla de Caseros en 1852. En esta etapa sucederán hechos nodales para la futura constitución y organización de la Argentina. Junto a los importantes eventos políticos, emergen producciones jurídicas y literarias de suma importancia.

Las primeras décadas del siglo XIX, estarán marcadas por la temática de la independencia. Serán una constante, la diferenciación y exclusión de toda perspectiva colonialista. Figurado desde los límites que comprende el territorio argentino para esos tiempos, la formación discursiva busca fundamentar una identidad estatal capaz de rechazar toda intervención foránea. Esta delimitación se verá plasmada en el contenido de las producciones epocales tanto en el derecho como la literatura.

Constantes cambios de gobierno, diferentes concepciones sobre la idea de 
representación, pugnas por el ejercicio del poder de manera central o federal, cuestionamientos sobre la legitimidad del gobierno y el sustento legal de sus actos. En estos términos, los dilemas iusfilosóficos se centran en el estudio de modelos de constitución del Estado bajo una norma general, la construcción de una identidad propia en el imaginario social, la justificación del fundamento de la autoridad, la articulación de los niveles del poder, el despliegue de la ideología.

Dada la novedad de sus propuestas, importantes instrumentos legales tendrán lugar en este período. La Asamblea General Constituyente, conocida como la Asamblea del Año XIII', adoptó el principio jurídico de la "Ley de vientres", ordenó reglamentos como el Estatuto del Supremo Poder Ejecutivo de Argentina ${ }^{3}$ y emitió disposiciones que decretaban la unicidad institucional e ideológica, como la "Marcha Patriótica en las Provincias Unidas del Río de la Plata", conocida luego como el Himno Nacional. Sentó las bases para el posterior desarrollo de sus dos propuestas centrales que no pudo llevar a cabo, por un lado declaración de la independencia, plasmada posteriormente en el Acta de la declaración de la Independencia de las Provincias de 1916 y por otro lado, la redacción de la Carta Magna.

La pertenencia física debía estar respaldada en la huella respetable que imprime la escritura con sustento en una ficción. Calvo González escribe en este sentido:

La Constitución es, por último, una ficción por ser Derecho. Sólo la mirada estrecha puede vincular la idea ficcional a simulación, engaño o fantasía. La ficcionalización constitucional, aunque tenga relación con determinadas etapas ideológicas de la gestación del texto, encuentra su momento determinante con la escritura de su relato. Es eso lo que, asimismo le sucede a toda posible escritura jurídica. La ficcionalización a la que me refiero es; así, el relato es la condición intra-ficcional del Derecho. Considerada desde la teoría narrativista la Constitución es ficción, es un gigantesco dispositivo ficcional, de trascendentales repercusiones para todo el sistema jurídico-político. La escritura del relato constitucional

\footnotetext{
${ }^{2}$ Congreso de diputados de las Provincias Unidas del Río de la Plata. Su duración fue desde el 31 de enero de 1813 hasta el 24 de enero de 1815.

${ }^{3}$ Instrumento legal aprobado el día 27 de febrero de 1813 con el fin de organizar y fijar las facultades del Poder Ejecutivo y se fijaron sus facultades.
} 
ficcionaliza la realidad porque la somete a un ars inventia disponendia, y así la constituye. (CALVO GONZÁLEZ, 2016a, pp. 54-55).

La monumental estructura se sostendrá en adelante sobre una hipótesis (KELSEN, 2010, pp. 150-157). La posterior aparición de la Constitución en 1853, propondrá un quiebre que supera el espacio jurídico. Su composición imprime una determinada forma de sociedad. Pero las formas de orden y organización no estaban claramente dirimidas. Las diferencias y luchas de poder corrieron la mirada de afuera y se centraron en la interioridad. La otredad ascendía nuevamente y se disputaba entre ideas centralistas y federalistas. Variadas especulaciones, debates doctrinarios y luchas armadas, dejaban entrever el carácter violento de la palabra jurídica. La historia de la Constitución no puede ser analizada sin tener en cuenta los acontecimientos bélicos de Caseros, Cepeda, Pavón ${ }^{4}$ y la aparición de figuras como Rosas, Urquiza, Mitre ${ }^{5}$. En estas instancias, los arqueos históricos se volverán laberínticos e inagotables.

Estos momentos puntuales y complejos del espacio jurídico serán circundados por una literatura antecedente y consecuente. Leyes, proclamas y dictámenes convivirán con textos literarios e incidirá la forma de su narrativa ${ }^{6}$. Esa cercanía será muy importante dada la función pedagógica que proponen.

Una obra se enclava como central, no solo por el peso de su autor sino por la capacidad anticipatoria del instrumento constitucional así como la densidad conceptual de su contenido. Ocho años antes de la aprobación de la Carta Magna, aparece Facundo o civilización y barbarie en las pampas argentinas (1845). Originalidad de un texto que se proyecta más allá de su esteticidad:

\footnotetext{
${ }^{4}$ En el orden citado, las batallas acontecieron el 1 de febrero de 1820, 3 de febrero de 1852 y 17 de septiembre de 1861 respectivamente.

${ }^{5}$ En el orden citado, ejercieron el poder ejecutivo entre 1835-1852, 1854-1860 у 1862-1868, respectivamente.

${ }^{6}$ Destáquese la importancia de los periódicos y revistas para la difusión de acontecimientos políticos y publicación de literatura nacional, v. gr. La Gaceta de Buenos Ayres, Telégrafo mercantil, El censor, El observador americano, Argos, La abeja argentina, El centinela.
} 
Su hipótesis se refiere a un texto que juega en los límites entre la novela y el ensayo, cuyo propósito es definir el cambio social desde su denuncia respecto a la violencia política en su época, reconociendo las cualidades estéticas que permiten acceder con mayor facilidad a su propuesta sociológica. Facundo representa un modelo de racionalidad y textualidad en las ciencias sociales latinoamericanas. (ALVARADO, 2000, p. 103)

El Facundo irrumpe como un centro desde el cual salen y hacia el cual llegan otras producciones literarias que mantienen las mismas preocupaciones de su tiempo como verdaderas luchas de emancipación.

El concepto de nación, el impulso del movimiento romanticista sumados al padecimiento del ostracismo retórico o físico, aglutinarán a toda una generación literaria. El compromiso y preocupación de los/as escritores/as que surgen, permiten un valioso espectro de herramientas para análisis iusfilosóficos. Sin poder agotar la totalidad de obras, podemos citar a El Corro (1820) de Juan Gualberto Godoy; Reflexiones sobre las causas morales de las convulsiones internas en los nuevos estados americanos y examen de los medios eficaces para reprimirlas (1836) de Juan Ignacio Gorriti; La cautiva (1837) y El Matadero (1839-1840) de Esteban Echeverría; El gigante Amapolas y sus formidables enemigos, o sea fastos dramáticos de una guerra memorable (1842) de Juan Bautista Alberdi; Misterios del Plata (1852) de Juana Manso. A ello su suman autoras/es como Catalina Allen de Bourel, Félix Frías, Florencio Varela, Rosa Guerra, Benjamín Villafañe, José Antonio Wilde, Juan María Gutiérrez, María Sánchez de Thompson, Pedro Echagüe, Petrona Rosende de Sierra.

De manera sintomática, la literatura se autopercibe como instrumento de compromiso social. Los variados géneros literarios permiten el ingreso de cuestiones políticas. En este sentido en la poesía se destaca La Lira Argentina o Colección de las piezas poéticas, dadas a luz en Buenos Aires durante la guerra de su Independencia (1824) de Vicente López y Planes, Esteban De Luca, Fray Cayetano Rodríguez, Juan Crisóstomo Lafinur, Juan Cruz Varela, Fray Francisco de Paula Castañeda, Antonio José Valdez. En la prosa serán El matadero (1840) de Estaban 
Echeverría y Amalia (1851) de José Mármol. Al igual que el Facundo, las obras nos instan a tomar posición ante la dicotomía binaria planteada desde los cuerpos textuales jurídicos: nacional o extranjero, ciudad o campo, conquista o desierto, unitario o federal, libertad o esclavitud, en definitiva, civilización o barbarie.

Estos escuetos pliegues literarios poseen una fuerte carga conceptual. Contienen toda una cosmovisión sobre las ideas de sistematización cultural de la Argentina y del derecho como relato que desde su escritura constituye el orden imaginario ficcional de la sociedad (CALVO GONZÁLEZ, 2018, pp. 349-364).

\section{ESCRITURA Y CONSTITUCIÓN DEL ESTADIO BÁRBARO}

Facundo, genio bárbaro, se apodera de su país; las tradiciones de gobierno desparecen, las formas se degradan, las leyes son un juguete en manos torpes.Facundo o civilización y barbarie en las pampas argentinas

\subsection{POESÍA}

La época de la emancipación fue poco propicia a la novela. La poesía o la simple versificación constituyeron la forma de acción literaria. En épocas de ideas y pretensiones independentistas de inicios del siglo XIX, El Cancionero de las invasiones inglesas (BARCIA, RAFFO, 2010, pp. 5-15) es un claro ejemplo de la activa participación de la literatura en torno a los hechos de su tiempo, en donde los conflictos militares se graficaban desde la estética poética. En este sentido, las composiciones que forman La Lira Argentina (1824) dan cuentas de la nueva literatura con aspiraciones de independencia. Iniciativa de fray José Camilo Henríquez González que no logra prosperar. Será en el marco de la celebración del sexto aniversario de la declaración de Mayo, donde aparece mediante el decreto del gobernador de Buenos Aires, Martín Rodríguez junto a su ministro y futuro presidente Bernardino Rivadavia. 
Una serie de encuentros y desencuentros, lo ubica a Ramón Díaz como compilador y editor de obra impresa en París. Considerada como el primer tomo de los anales de la poesía del Río de la Plata, el conjunto de los poemas patrióticos escritos representaron un homenaje a la Revolución de Mayo y a las grandes gestas patrióticas que le siguieron. Al mismo tiempo, se daba cumplimiento a la primera hazaña editorial argentina: "En sus quinientas veinte páginas reúne ciento dieciocho composiciones, y sólo están presentes los panegiristas de Mayo y de los hechos revolucionarios" (FUCITO, 2010, p. 68).

Las composiciones intentaban reflejar el apasionamiento y el vigor expresivo de estos cantores inaugurales de la nacionalidad. La patria recién nacida es para ellos, el motivo poético por excelencia y así lo expresa Fray Cayetano Rodríguez, uno de los poetas más celebrados de la época: "La patria es una nueva musa que influye divinamente" (CASIVA, 2006, p. 325).

Desde la Marcha Patriótica de Vicente López y Planes, la Canción Patriótica de Esteban de Luca o los gritos de libertad de Fray Cayetano Rodríguez en su Oda, se proclama y da cuentas de un nuevo proceso signado por la autodeterminación, la necesidad de la constitución de un orden y el sostenimiento del derecho patrio frente a la opresión y la injusta violencia del colonizador: "El padre a sus hijos / Pueda decir: / 'Gozad de derechos / Que no conocí'” (ROSEMBERG, 1967, p. 15).

Los triunfos de las armas patrióticas, la muerte de los héroes y la esperanza de la libertad inspiraron una poesía vehemente, exaltada, en la que se conjugan los recursos poéticos del neoclasicismo con los hombres y la tierra americana. Las pretensiones de libertad que se desprenden de sus líneas superan y dejan en un segundo plano el aspecto estético (HÄBERLE; LÓPEZ BOFILL, 2015, pp. 46-59). La acción predomina sobre la dicción e invita a constituir las nuevas bases y lineamientos que hacen de la literatura y todos los espacios sociales una Argentina independizada a principios del siglo XIX, un proceso diferenciado de los modelos 
europeos:

La América al fin entró / Al goce de sus derecho / Así quedan satisfechos / Tantos suspiros que dio. / Su constancia consiguió / Destruir al maquiavelismo / Y hacer que con heroísmo / Jure todo americano / Eterna guerra el tirano, / Guerra eterna al despotismo. (ROSEMBERG, 1967, p. 87)

La lira argentina manifiesta el surgimiento de la nacionalidad. Se destacan allí las ideas de patria y nación, se exige el cambio de lenguaje como propuesta de cambio representacional del entorno (BALDERSTON, FOSTER, HALPERIN DONGHI, MASIELLO, MORELLO FROSCH, SARLO, 2014, p. 18). Las palabras sostienen y fundan las nuevas perspectivas independentistas que pretenden erigirse. La fibra heroica adquiere su entusiasmo por un lado por la diferencia que se establece con el invasor en términos étnico, religiosos, lingüísticos, políticos, ideológicos. Por otro lado, las memorias, las tertulias, estados de ánimos que incitan a la producción inmediata de una literatura revolucionaria, capaz de expresar un sentimiento mítico, comprimido y denso de identidad compartida:

No será así: gozosa se sonríe / La humanidad con tal plausible nueva. / Vedla volver sus ojos con ternura / Saludando a este asilo venturoso / Desde Asia y Europa, donde gime / En medio de la paz de los sepulcros. / Que atreviese el Atlántico; la esperan Leyes humanas bajo un dulce clima / Y en los campos inmensos la abundancia. (ROSEMBERG, 1967, p. 90)

\subsection{PROSA}

Si en épocas del proceso independentista, la poesía fue la forma de expresión característica, en los años de tiranía, caudillismo, centralismo y ostracismo, la prosa ocupará la centralidad. Una forma literaria que establecerá vínculos el movimiento artístico literario del romanticismo:

Es precisamente este romanticismo, incorporando ideas de Herder, de 
Savigny y Vico que hace pie, entre otros textos, en el Dogma socialista de Esteban Echeverría, en Fragmento preliminar al estudio del derecho de Juan Bautista Alberdi y, agrega Torchia Estrada, en el Facundo de Sarmiento, y en la Memoria sobre los resultados generales con que los pueblos antiguos han contribuido a la civilización de la humanidad, de Vicente Fidel López. (...) Todos ellos, tomaron una franca actividad política liberal y contraria al gobierno de Rosas, lo que les valió el exilio, retornando luego de la batalla de Caseros a seguir su obra. (MARÍ, 2002, p. 215)

El romanticismo expondrá sus marcas distintivas en el desarrollo de la originalidad, la creatividad, el subjetivismo e individualismo, la libertad de la métrica y el culto a la idea del espíritu del pueblo. Argentina no será la excepción, en donde "el Romanticismo entra en Buenos Aires importado de Francia por Esteban Echeverría” (FUCITO, 2010, p. 91).

El autor argentino, pertenece al movimiento intelectual conocido como la “generación del 37”, la cual mantiene una marcada posición política. Su poema épico, La cautiva (1837) abrirá las puertas al romanticismo rioplatense. Dicha producción, interpelará el espacio jurídico al exponer las costumbres que no se adecuan al canon de civilización, nación y estética de pueblo (GALATI, 2015, pp. 131-138). Relato heroico que democratiza su lectura desde sus espacios comunes. Una mujer fortalecida, un soldado de pueblo, el sanguinario y feroz indio, la pampa latente: "Súbito ella se incorpora; / de la pasión que atesora / el espíritu inmortal / brota en su faz la belleza, / estampando fortaleza / de criatura celestial, / no sujeta a ley humana" (ECHEVERRÍA, 1967, p. 41).

Si La cautiva presenta la problemática por fuera de las fronteras de la ciudad, El matadero (1938) lo hará hacia su interior. La pugna por el poder, los abusos y el modo de entender la justicia desde la dicotomía entre unitarios y federales, se plantean desde las aperturas y los velos que permite la cruda y realista metáfora literaria. Actos atroces se vinculan con viles lenguajes. La defensa literaria se propone desde el ataque directo a lo que acontece en los corrales de la época rosista, en donde al compás de alguna refalosa, los matarifes de cuño federal ejercen juicios ad hoc que 
se debaten entre la retórica y la violencia.

Todo en El matadero parece desbordarse. Se exagera, se agranda y espectaculariza. Las ideas totalizantes de cuño religioso, las jaurías, las bandadas de rapiña, los brillos de los cuchillos, la algarabía de los carniceros (RODRÍGUEZ, SALVADOR, 2005, p. 78). La escena aturde, repugna, molesta. Un tumulto constante de cuerpos armados signados por la bestialidad:

- ¿No sabes que lo manda el Restaurador? / - La librea es para vosotros, esclavos, no para los hombres libres. / - A los libres se les hace llevar a la fuerza. / - Sí, la fuerza y la violencia bestial. Esas son vuestras armas, infames ¡El lobo, el tigre, la pantera, también son fuertes como vosotros! Deberíais andar como ellos, en cuatro patas. (ECHEVERRÍA, 1967, p. 41)

El cuadro obsceno (ob-scenus) se presenta bajo un rojo intenso, como un bambalinón capaz de aforar lo que sucede (LOJO, 1991, pp. 42-45). Lo jurídico será un tema cardinal aquí. Las formas de juzgamiento ocuparán parte esencial en su armado para concluir en el calvario del joven unitario, sacrificio necesario para hacer emerger la obra. Una muerte inimputable, desconocida, nadie ha puesto su mano. Sin embargo, la falta de contacto con el cuerpo no implica la ausencia de la violencia que permite el carácter inmaterial del poder jurídico.

El cuerpo no muestra lo que la ley ya imprimió con antelación. A simple vista, el sujeto ha muerto sin intervención de terceros. Para ello será necesaria la figura del juez:

Juez del matadero, personaje importante, caudillo de los carniceros y que ejerce la suma de poder en aquella pequeña república, por delegación del Restaurador. Fácil es calcular qué clase de hombre se requiere para el desempeño de semejante cargo. (ECHEVERRÍA, 1967, p. 68)

Su persona conduce la escena y maneja el relato, permite la consecución de la obra y de todo lo que en ella sucede: 


\begin{abstract}
Alguna tía vieja salí furiosa en persecución de un muchacho que le había embadurnado el rostro con sangre, y acudiendo a sus gritos y puteadas los compañeros del rapaz, la rodeaban y azuzaban como los perros al toro, y llovían sobre ella zoquetes de carne, bolas de estiércol, con groseras carcajadas y gritos frecuentes, hasta que el juez mandaba restablecer el orden y despejar el campo. (ECHEVERRÍA, 1967, p. 71)
\end{abstract}

En ese ambiente reducido, el mismo Echeverría rompe el estado literario y reconoce una clara identificación mimética con la realidad. Todo lo que sucede allí bien acontece de manera difusa pero articulada en todos los intersticios de la sociedad, entre los cuales se encuentra el espacio jurídico: "Simulacro en pequeño era este del modo bárbaro con que se ventilan en nuestro país las cuestiones y los derechos individuales y sociales" (ECHEVERRÍA, 1967, p. 71).

Sin poder sostener el efecto ficcional, Echeverría constantemente se entromete indirectamente en la obra. A través de sus personajes, la alegoría y la semejanza, tendrá sus opiniones sin reparos, en tanto entiende el vínculo que existe entre lo literario, lo jurídico y lo político. Estos espacios deben comprenderse en el programa estético de la literatura, la cual debe "revestir un carácter propio y original, debe reflejar los colores de la naturaleza física que no rodea, sea a la vez el cuadro vivo de nuestras costumbres, y la expresión más elevada de nuestras ideas dominantes" (ECHEVERRÍA, 1967, p. 81).

Pinceladas de fina ironía pretenden dar cuenta, tal como lo indica en el Dogma Socialista, como la literatura funciona como instrumento de denuncia y de cambio frente a la práctica política y el ejercicio arbitrario de los derechos:

\footnotetext{
Malgastaríamos el trabajo estérilmente, echaríamos un nuevo germen de desacuerdo, destructor de la homogeneidad y armonía del progreso americano, para acabar por no entendernos en literatura, como no nos entendemos en política. (...) nos parece absurdo ser español en la literatura y americano en política. (ECHEVERRÍA, 1967, p. 112)
}

En este espacio, se destacará otra obra representativa de la prosa romanticista. Amalia, de José Mármol, será la primera y más popular novela argentina, traducida 
en varias lenguas y fomentadora de obras teatrales y cinematográficas. Lo que permite hablar no solo de un cuerpo literario que destaca al Mármol novelista sobre el poeta, sino de un valioso documento social, histórico y jurídico.

Una historia de amor mediada por las implicancias políticas, sociales y legales contextualizadas en la Confederación Argentina, durante el mandato del político y militar Juan Manuel de Rosas. Las persecuciones ideológicas, las proscripciones confinadas al destierro, las detenciones sin justa causa, las constantes intervenciones en la vida privada, la imposibilidad de reunión, la inminente necesidad de exiliarse en el exterior por sostener otro pensamiento político, la violencia como forma de acceso a la justicia, son los avatares por los cuales transcurre Amalia y que no pueden entenderse sin analizar los efectos que las decisiones del gobierno rosista tuvieron en las relaciones humanas: "Si nadie me hace justicia, aquí está quien me la ha de hacer (...), señalando el lugar de la cintura en que acababa de guardar su cuchillo, bajo un enorme chaleco dorado" (MÁRMOL, 1967, p. 23).

No podemos escindir toda producción sin ubicar espacio-temporalmente al individuo que la realiza así como tampoco podemos entender un hecho o acontecimiento sin al menos intentar comprender la totalidad de causas que lo provocan. Ambas consideraciones nos llevan a reflexionar que para entender Amalia es necesario ubicar históricamente a su autor. Al igual que sus personajes, José Mármol es producto de su época, se encuentra mediado por las circunstancias que lo implican. Para Mármol la participación política y la producción literaria serán dos caras de una misma moneda. Desde sus primeros intentos por introducir otras perspectivas ideológicas en la Argentina, el autor de Amalia se vio enfrentado al poder de turno, encabezado por Juan Manuel de Rosas. La concatenación de hechos en los cuales se verá implicado, como su breve paso por la prisión, lo va a posicionar políticamente en sus producciones. No hay que esperarse un sinfín de metáforas, ni nombres inventados cuyas iniciales coinciden con la de personajes reales de la época, tampoco atajarse de antemano que vamos tener que interpretar un sinfín de ironías, 
por el contrario, desde sus primeras páginas y rodeada de un ambiente enigmático, Amalia, nos pone al tanto de cuál es su posicionamiento.

Su escritura tendrá una doble función. Por un lado, una función estéticainformativa. Sus textos signados por el romanticismo, deja ver todo su temperamento apasionado, las ideas como grandes estandartes, los aires de libertad poetizados, los sentimientos que se imponen y protegen al amor alado frente a todo pensamiento racional. Por otro lado, será una función performativa. En este intento de transmitir conocimientos, el texto literario constituye subjetividades. Las máximas que se pueden identificar y resaltar en las lecturas son instrumentos y herramientas para posicionar el conocimiento de una determinada manera. El acto de construcción del relato de Amalia va unido a todo un acopio social. José Mármol no es su productor ascético sino que lleva consigo toda una carga de intereses, emociones, motivaciones y elecciones propias. Amalia y su narración narran a lo largo de sus cinco partes, una manera de pensar al imaginario jurídico.

\subsection{ECLECTICISMO Y UNIÓN}

Varias formas de clasificación son posibles en tanto hablamos de posiciones jurídicas, políticas o literarias. La forma de clasificación de una obra bien puede pensarse desde su estructura interna o desde hechos externos. Si indagamos en esta última forma, podríamos reunir autores que han compartido características comunes en términos políticos-jurídicos como es el caso del destierro. El análisis político desde esta circunstancia proscriptiva, se plasmará en las obras literarias:

La obra de los proscriptos ha de buscarse, por un parte, en los géneros propiamente literarios- novela, teatro y poesía - fuertemente influidos todos ellos por la política, y, por otra, donde el acervo es más abundante, en el periodismo partidista, en la oratoria dentro y fuera del Parlamento, en la prosa constructiva. (DARNET DE FERREYRA, 1950, p. 266)

Escrita en el exilio, la obra Facundo o civilización y barbarie en las pampas 
argentinas (en adelante Facundo) de Domingo Faustino Sarmiento, es considerada una de las obras más importantes de la literatura hispanoamericana. Ella no solo representa un gran desarrollo a nivel literario, sino un profuso estudio político, jurídico, sociológico, geográfico y antropológico de su época:

El Facundo no es sociológico - aunque alude a una perspectiva social., ni tampoco biografía, ni ensayo histórico, ni novela, sino combinación de todo ello. Lo mismo puede decirse de Amalia de J. Mármol. Todas estas obras buscan analizar la realidad social y política del país y tratar de entender las causas del gobierno imperante. (FUCITO, 2010, p. 105)

Para comprender las consideraciones que se desgajan desde la óptica “civilización y barbarie" (PIGLIA, 2016, p. 52), debemos incursionar en el contexto y las implicancias que éste tuvo en la espada, la pluma y la palabra de su autor:

Un gran libro, un libro que tiene la estructura de un espejismo. (...) Construye una interpretación que dura hasta hoy, podríamos llamarla la mirada extralocal (...) Lo real es falso, hay que construir una copia verdadera. Lo notable es que ese libro ha logrado imponer esa duplicación como construcción histórica. En lo real todo parece estar desdoblado, el juego de oposiciones prolifera; en ese sentido el Facundo es como un virus: todos los que lo leen empiezan a ver civilizados y bárbaros. (PIGLIA, 2014, p. 25)

Precursora del subgénero "novela del dictador", da muestras de las conexiones existentes ente el poder y todos los ámbitos sociales. Desde un punto de vista puntualmente jurídico, la dicotomía expuesta por Sarmiento nos indica la pugna existente en el siglo XIX en torno a la necesidad de institucionalizar el derecho. Sobre dicho terreno, el mismo autor, años más tarde se pronunciará de forma inmediata y a libro cerrado sobre el proyecto del Código Civil de Vélez Sarsfield.

La bipolaridad conceptual "civilización-barbarie" es el recurso metafórico del que se vale el escritor a fin de dar cuentas y ponderar el pensamiento civilizado, constitucional, europeo por sobre el pensamiento bárbaro, arbitrario y americano. Facundo se presenta inabarcable (UNAMUNO, 1957, pp. 89-95). Su lectura es 
pasible de análisis desde una multiplicidad de disciplinas. Cada línea nos obliga a tener conocimientos de las diferentes ramas del saber. Hemos de encontrar elementos geográficos que nos hacen caminar por las tierras desconocidas, análisis antropológicos que nos dan cuenta de las facciones y concepciones del individuo, consideraciones políticas que de un modo u otro moldean el pensamiento nacional, instrumentos jurídicos que buscarán basamento en concepciones iusfilosóficas, estudios sociológicos que nos muestran la conformación de la Argentina del siglo XIX.

El Facundo es una máquina polifacética: tiene circuitos, cables, funciones variadísimas, está llena de engranajes que conectan redes eléctricas, trabaja con todos los materiales y todos los géneros. En ese sentido funda una tradición. La serie argentina del libro extraño que une el ensayo, el panfleto, la ficción, la teoría, el relato de viajes, la autobiografía. Libros que son como lugares de condensación de elementos literarios, políticos, filosóficos, esotéricos. En el fondo esos libros son mapas, hojas de ruta para orientarse en el desierto argentino. (PIGLIA, 2014, pp. 25-26)

Su obra tendrá esa capacidad de condensar un sentido, que recorre desde los primeros días de la independencia hasta el momento en el que se sientan las bases jurídicas de la Nación Argentina. Y como tal, delimita formas de visualización tanto en el aspecto literario como en el jurídico. Facundo se presenta de manera ecléctica y difícilmente clasificable bajo un canon exclusivo. Diversas serán las posiciones respecto de la forma de clasificación del texto. Pensado como un contrato de lectura, el género literario establece un acuerdo entre el autor y el lector con un previsible derrotero de lectura. Sin embargo:

El Facundo no permite que el lector mantenga un programa genérico constante; esta no es una estrategia particularmente inusual, puesto que el desafío de las convenciones genéricas es un procedimiento frecuente que aguza el interés, ni hay que olvidar que esta heterogeneidad se ajusta a los códigos literarios vigentes en la época de composición del texto. Pero lo excepcional aquí es que el lector se ve obligado a cambiar de programas, de una porción del texto a la otra, ajustando su actitud de lectura según exigencias bastante heterogéneas, por lo que se dan clasificaciones 
variadas. (SORENSEN GOODRICH, 1988, p. 574)

Profusamente traducido, sujeto a una miríada de estudios desde las más diversas ópticas hacen que sea una de las obras más estudiado del período. En ella corren en simultáneo dos textualidades diferentes pero con un mismo punto de contacto, en tanto se presenta como un ensayo sociológico que recurre a los recursos y estrategias propios de la novela:

La perspectiva ética inherente al texto es por lo tanto el puente que une la defensa de valores propia del ensayo con la dimensión eminentemente estética de la novela: por ello los valores de Sarmiento se constituye en una estrategia narrativa primordial. (ALVARADO, 2000, p. 107)

Desde una perspectiva jurídica, la obra también habilita los estudios iusliterarios. En Facundo, el análisis de la Constitución tendrá un papel nodal:

Los conflictos jurídicos y culturales se hicieron evidentes en el choque entre el proyecto del país que, (...) anunciado ya en el Facundo (es decir, como lo indica el subtítulo referido, Civilización y Barbarie) y plasmado en la Constitución de 1853-60. (CALVO GONZÁLEZ, 2008, pp. 3-28)

Facundo condensa la prosa. Lejos de reducirse a una crítica puntual a la figura de Rosas, su propósito se atomiza a la generalidad cultural (RODRÍGUEZ PÉRSICO, 2012, pp. 15-25). La dicotomía será necesaria así para poder expresar no solo la voluntad jurídica del pueblo argentino adosada a dirigencias bien personalizadas, sino "también un mundo que estaba en el porvenir y otro que se iba retirando" (CIURO CALDANI, 1986, p. 108). Tanto en términos literarios como jurídicos, la obra logra la ubicuidad al reactualizar dilemas sociales. Estos binomios se presentan como independentismo-colonialismo, centralismo-federalismo, civilización-barbarie. El análisis se presenta en términos duales y Sarmiento toma posición: "Había antes de 1810 en la República Argentina dos sociedades distintas, rivales e incompatible; dos civilizaciones diversas; la una española, europea, 
civilizada, y la otra bárbara, americana, casi indígena" (SARMIENTO, 1962, p. 59).

Desde allí, el Facundo congrega una idea determinada para constituir la Argentina a los fines de continuar "la obra de rehabilitación de lo justo y de lo digno" (SARMIENTO, 1962, p. 19). Necesidad de establecer el orden constitucional del país en términos legales, a los fines de consolidar el cambio político. Sus aportes lo llevarán a ser considerado uno de los principales precursores del movimiento constitucional junto a Juan Bautista Alberdi, cuyas diferencias y enconos se verán de plasmados en varios de sus textos, para luego encontrarse nuevamente en otras circunstancias al momento de llevar a cabo el Código Civil (D’AURIA, 2004, p. 277).

La relación de Sarmiento con el espacio Constitucional desde la lectura del Facundo permite interesantes posibilidades iusliterarias (CLAVELL, 2015, pp. 2226; PALADIN, 2011, pp. 47-56). Juan Vicente Sola sostiene que: "Su principal contribución y la que perdura en la Argentina moderna por encima de los demás constituyentes es su visión de la Constitución como un proceso (VICENTE SOLÁ, 2016, pp. 5-36).

En el Facundo, se expone esta intención de unir la nación desde la legitimidad. El contrato social expresado en términos constitucionales debía ser llevado a cabo mediante la delimitación de los espacios. En este sentido, su compromiso pedagógico, sus ideas, sus profusas lecturas, el espacio de su intimidad, el género escindido desde su visión dual de la cultura, su construcción de la otredad, las impresiones de sus viajes que abren su función periodística y las experiencias constitucionales de otras latitudes, son elementos para comprender su posición. Sarlo expone:

Cuando escribe Facundo, Sarmiento no conoce Buenos Aires; tampoco conoce Córdoba, ni Tucumán. Escribe de lo que no ha visto jamás: escribe con los libros sobre la mesa, a partir de testimonios de viajeros y de lo que ha oído decir; se acerca a la ciudad desde afuera, desde ciudades extranjeras o imaginadas. Para Sarmiento, ciudad y cultura, ciudad y república, ciudad e instituciones son sinónimos trabados por una inseparable relación formal y conceptual. Cree que en la ciudad está la virtud y que la ciudad es el 
motor expansivo de la civilización. La extensión rural es despótica, el agrupamiento urbano incuba a la república. Sarmiento, con un gesto voluntarista de creación imaginaria de la sociedad por venir, profetiza una ciudad y una cultura a las que sólo después de medio siglo se aproxima Buenos Aires. (SARLO, 2015, p. 7)

Esta posición que existe entre lo que Sarmiento habita y lo que desea habitar da cuentas de una distancia que solo puede aproximarse desde lo textual, tanto en términos literarios como jurídicos. Lo mismo pasará con la figura del Facundo, devenido en personaje. Lo conoce por sus expedientes cargados de sangre e insensibilidad, por un hombre literato que le ha suministrado manuscritos de sus primeros años, por esa imagen que raya inevitablemente con la natural bestialidad:

Facundo es un tipo de la barbarie primitiva; no conoció sujeción de ningún género; su cólera era la de las fieras; la melena des sus renegridos y ensortijados cabellos caía sobre su frente y sus ojos en guedejas, como las serpientes de la cabeza de Medusa; su voz se enronquecía, sus miradas se convertían en puñaladas. (SARMIENTO, 1962, p. 83)

La obra se proyecta desde una exposición "combativa, agresiva y panfletaria" (FUCITO, 2010, p. 121). La dicotomía dialéctica entre civilización y barbarie será planteada en términos cualitativos y cuantitativos. Lo bárbaro se construye desde la carencia de todo orden jurídico: "Así es como en la vida argentina empieza a establecerse por estas peculiaridades el predominio de la fuerza brutal, la preponderancia del más fuerte, la autoridad sin límites y sin responsabilidad de los que mandan, la justicia administrada sin formas y sin debate" (SARMIENTO, 1962, p. 29).

Las referencias sobre la institucionalidad jurídica pululan de manera expresa y clara en el Facundo:

He mostrado la asociación ficticia, en la desocupación; en la formación de las reputaciones gauchas; valor, arrojo, destreza, violencia y oposición al a justicia regular, a la justicia civil de la ciudad. Este fenómeno de organización social existía en 1810, existe aún, modificado en muchos puntos, modificándose lentamente en otros e intacto en mucho aún. 
(SARMIENTO, 1962, p. 59)

Radiografía de una época que hereda una justicia de la tradición virreinal y un ejercicio discutible de la justicia:

En una población de cuarenta mil habitantes reunidos en una ciudad, no hay un solo abogado hijo del país ni de las otras provincias. Todos los tribunales están desempeñados por hombres que no tienen el más leve conocimiento del derecho, y que son, además, hombres estúpidos en toda la extensión de la palabra. (SARMIENTO, 1962, p. 69)

Se trata de una anomia que se traduce de manera paradojal en el ejercicio de jueces constituidos por la arbitrariedad histórica, por su largo letargo en el cargo y la figura de un individuo que vive al margen, que entiende otras formas de ejercer la justicia "y destruye la obra de los siglos, la civilización, las leyes y la libertad" SARMIENTO, 1962, p. 60).

Facundo grafica a un individuo que desconoce la norma porque no sabe leer, ese que deja "tendido al juez de una puñalada" (SARMIENTO, 1962, p. 79), que trunca la posibilidad de proyectar normas, que se pierde en la anárquica y desconocida extensión geográfica. Su autor superpone la idea sobre la experiencia. La fuerza conceptual utópica por la política de a caballo y cuchillo. No siente la necesidad de recorrer la extensión, mientras ocupe el centro. Desde allí, desde la idea unitaria de gobierno, caracterizada por "tradiciones, costumbres, formas, garantías, leyes, cultos, ideas, conciencia, vida, haciendas, preocupaciones" (SARMIENTO, 1962, p. 203). En detrimento de una forma federal, encargada de:

Derogar todas la leyes existentes en la República desde al año 1810 adelante, aunque hayan sido dictadas por los congresos generales o cualquiera otra autoridad competente; declarando, además, irrito y sin ningún valor todo lo que a consecuencia y en cumplimiento de esas leyes se hubiese obrado hasta entonces. (SARMIENTO, 1962, p. 218) 
El drama se impone sobre la acción. La pretensión política de favorecer la revolución de Sarmiento, como el mismo lo reconocerá (KAPLAN, 1997, pp. 729733), excede lo meramente literario. El relato despista la lectura unívoca y presenta una pluralidad de estrategias de lecturas. Como indica Sorensen Goodrich: "Facundo y sus intérpretes han llevado la discusión hasta el terreno de la ética y, por lo tanto, se presentan a la consideración de esa zona en que lo textual y lo social interactúan" (SORENSEN GOODRICH, 1988, p. 574).

Sarmiento se ocupa en su pluma y preocupa a sus congéneres por la organización de la ideología federal y la falta de una Constitución unitaria. Los instrumentos jurídicos se establecen como los límites ideológicos y en ello tendrá una gran fuerza motriz el uso del binomio civilización-barbarie. Organizar, dar orden, constituir desde el derecho implica en definitiva una forma de articular y edificar la cultura argentina en su totalidad:

Sarmiento escribe entonces en francés una cita que atribuye a Fourtol, si bien Groussac se apresura, con la amabilidad que le conocemos, a hacer notar que Sarmiento se equivoca. La frase no es de Fourtol, es de Volney. O sea, dice Renzi, que la literatura argentina se inicia con una frase escrita en francés, que es una cita falsa, equivocada. (PIGLIA, 1980, p. 17)

\section{CONCLUSIONES}

La ficción literaria literatura escribe, reestructura, comenta y trazan sucesos que no necesariamente hacen a su tiempo. En un avance o un retroceso, el texto relata a su manera lo acontecido desde la atemporalidad. Desde allí, bien puede analizarse el espacio jurídico. La mirada lejana y ajena que vuelve a relatar su acontecer permite tener otra perspectiva, nuevas miradas y percepciones de lo acontecido. Esa nueva lectura permite visibilizar nuevos espacios e intersticios que no se han resaltado.

El proceso de emergencia de una obra demanda la indagación en torno a cuestiones que parecen opacar su verdadero sentido. Ahora bien, ¿cuál es ese sentido, 
sino aquel que le ha querido dar su autor? Sin embargo, estos interrogantes se trasladan en tanto figuremos la idea de autor en tanto individuo libre y autónomo ante una escritura que se la presenta abierta y plena. La obra se rodea de otras obras, que de manera satelital arriban a ella o emergen de ella. Así, la narrativa implica también sus condiciones de producción y lectura. La capacidad textual de relatar su época. Sobre ello cabe preguntarnos: ¿qué espacio ocupa el derecho en el momento mismo que la obra emerge?

El desvelo que produce la fuerza de la palabra será un dato nodal en los autores de La Lira Argentina, El matadero, Amalia o Facundo. Todos ellos escriben. La escritura como ejercicio de intervención cultural cuestiona sus modos. Será desde los silencios, los murmullos y los ruidos como formas en que las palabras se despliegan, desde los cuales podremos analizar, demonstrar y volver a narrar los estrechos espacios entre el derecho y la literatura.

Variados en sus formas y representaciones, discutidos en su formación, nos enfrentamos a lo largo de la historia argentina a diferentes formas de concebir y desarrollar tanto la literatura como el derecho. Bien puede pensarse en un desarrollo crítico-deconstructivo tanto de uno como de otro espacio, que visibilice el entramado interno que permite su constitución. Así será pensada como una obra, un código. Esta fuerza estética no sólo será desde un nivel externo, también podrá apreciarse en los marcos internos de cada uno de esos cuerpos textuales.

Allí el aspecto narrativo, la estructura ficcional, la capacidad de intervenir en la cultura, la carga ideológica de la escritura, serán elementos que figuran tanto en el espacio literario como jurídico. En conclusión, estos contactos iusliterarios proponen nuevos espacios de análisis en torno al carácter performativo, la reglamentación, el orden, la regulación y la intervención en el imaginario por parte del derecho. 


\section{REFERENCIAS}

ALVARADO, Miguel. La estrategia narrativa de una utopía abierta en Facundo, de Domingo Faustino Sarmiento. Literatura y lingüística, n. 12, pp. 103-118, 2000.

ARLT, Roberto. El juguete rabioso. Buenos Aires, Centro Editor de Cultura, 2004.

BALDERSTON, Daniel; FOSTER, David W.; HALPERIN DONGHI, Tulio; MASIELLO, Francine; MORELLO FROSCH, Marta; SARLO, Beatriz. Ficción y política. La narrativa argentina durante el proceso militar. Buenos Aires, Eudeba, 2014.

BARCIA, Pedro Luis; RAFFO, Josefina. Cancionero de las invasiones inglesas. Buenos Aires, Emecé, 2010.

BORGES, Jorge Luis. Poesía completa. Buenos Aires, Debolsillo, 2013.

CALVO GONZÁLEZ, José (coord.). Implicación Derecho Literatura. Contribuciones a una teoría literaria del derecho. Granada, Comares, 2008.

CALVO GONZÁLEZ, José. De la ley ¿O será ficción? Madrid, Marcial Pons, 2016.

CALVO GONZÁLEZ, José. Justicia constitucional y literatura. Lima, Centro de Estudios Constitucionales del Tribunal Constitucional, 2016.

CALVO GONZÁLEZ, José. La destreza de Judith. Estudios de cultura literaria del derecho. Granada, Comares, 2018.

CALVO GONZÁleZ, José. Proceso y narración. Teoría y práctica del narrativismo jurídico. Lima, Palestra, 2019.

CÁRCOVA, Carlos María; DOUGLAS PRICE, Jorge; RUIZ, Alicia. La letra y la ley. Buenos Aires, Infojus, 2014.

CASIVA, Fernando. Poéticas de fundación en La Lira Argentina. Revista Escuela de Historia, v. 5, n. 5, pp. 323-337, 2006.

CIURO CALDANI, Miguel Ángel. El Derecho y el arte. Revista del Centro de Investigaciones de Filosofía Jurídica y Filosofía Social, n. 14, pp. 37-41, 1991. 
CIURO CALDANI, Miguel Ángel. Filosofía, Literatura y Derecho. Rosario, Fundación para las Investigaciones Jurídicas, 1986.

CLAVELL, Marga. "La justicia bárbara": Sarmiento y la tragicidad del derecho en Facundo. Buenos Aires, Corregidor, 2015.

D’AURIA, Aníbal. Comentario a Comentarios de la Constitución de la Confederación Argentina. Revista Academia, vol. 2, nº 4, pp. 273-277, 2004.

DARNET DE FERREYRA, Ana Julia. Historia de la Literatura Americana y Argentina. Buenos Aires, Estrada, 1950.

ECHEVERRÍA, Esteban. La cautiva, El matadero y otros escritos. Buenos Aires, Centro Editor de América Latina, 1967.

FOUCAULT, Michel. La arqueología del saber. Buenos Aires, Siglo XXI, 2008.

FUCITO, Felipe. La crisis del derecho en la argentina y sus antecedentes literarios. Un enfoque sociológico. Buenos Aires, Eudeba, 2010.

GALATI, Elvio. La costumbre en el derecho argentino: análisis jusfilosófico y trialista de la "razón" del pueblo. Buenos Aires, Teseo, 2015.

HÄBERLE, Peter; LÓPEZ BOFILL, Héctor. Poesía y derecho constitucional. Una conversación. Lima, Centro de Estudios Constitucionales, 2015.

KAPLAN, Marina. Reseña Diana Sorensen Goodrich, "Facundo" and the Construction of Argentine Culture. Revista Iberoamericana, v. 63, n. 181, pp. 729733, 1997.

KELSEN, Hans. La función de la Constitución. Revista Electrónica del Instituto de Investigaciones 'Ambrosio L. Gioja', v. 4, n. 5, pp. 150-157, 2010.

LOJO, María Rosa. El Matadero de Esteban Echeverría: la sangre derramada y la estética de la "mezcla". Revista Alba de América, v. 9, n. 16-17, pp. 42 a 45, 1991.

MARÍ, Enrique. La Teoría de las Ficciones. Buenos Aires, Eudeba, 2002.

MÁRMOL, José. Amalia, vol. I-II. Buenos Aires, Centro Editor de América Latina, 1967. 
MARTYNIUK, Claudio. Jirones de piel, ágape insumiso. Estética, epistemología y normatividad. Buenos Aires, Prometeo, 2011.

MARTYNIUK, Claudio. Sobre la norma del gusto, la normatividad del arte y la narración de la justicia. Buenos Aires, Coyoacán, 2006.

PALADIN, Gabriela. Hombres de ley, hombres sin ley: cruces entre derecho y literatura. Buenos Aires, Biblos, 2011.

PIGLIA, Ricardo. Crítica y ficción. Buenos Aires, Debolsillo, 2014.

PIGLIA, Ricardo. Las tres vanguardias. Saer, Puig, Walsh. Buenos Aires, Eterna Cadencia, 2016.

PIGLIA, Ricardo. Notas sobre Facundo. Punto de vista, v. 3, n. 8, pp. 15-18, 1980.

RODRÍGUEZ PÉRSICO, Adriana. El estado de la cultura. Estudios de Teoría Literaria - Revista digital: artes, letras y humanidades, v. 1, n. 1, pp. 15-25, 2012.

RODRÍGUEZ, Juan Carlos; SALVADOR, Álvaro. Introducción al estudio de la literatura hispanoamericana, Madrid, Akal, 2005.

ROGGERO, Jorge (comp.). Derecho y literatura. Textos y contextos. Buenos Aires, Eudeba, 2015.

ROSEMBERG, Fernando (ed.). La Lira Argentina o Colección de las piezas poéticas, dadas a luz en Buenos Aires durante la guerra de su Independencia, Buenos Aires, Centro Editor de América Latina, 1967.

SARLO, Beatriz. Borges, un escritor en las orillas. Buenos Aires, Siglo XXI, 2015.

SARMIENTO, Domingo Faustino. Facundo o civilización y barbarie en las pampas argentinas. Buenos Aires, Sopena, 1962.

SORENSEN GOODRICH, Diana. Facundo y los riesgos de la ficción. Revista Iberoamericana, v. 54, n. 143, pp. 573-583, 1988.

UNAMUNO, Miguel De. Algunas consideraciones sobre la literatura hispanoamericana. Madrid, Espasa-Calpe, 1957.

VICENTE SOLÁ, Juan. Sarmiento y la Constitución. Buenos Aires, Academia Nacional de Ciencias Morales y Políticas, 2016. 
Data da submissão: 21/05/2021

Data da aprovação: 05/07/2021 